\title{
Measurement of body fat in young and elderly women: comparison between a four-compartment model and widely used reference methods
}

\author{
BY JANNEKE A. BERGSMA-KADIJK, BRIGITTE BAUMEISTER \\ AND PAUL DEURENBERG \\ Department of Human Nutrition, Wageningen Agricultural University, Bomenweg 2, 6703 HD \\ Wageningen, The Netherlands
}

(Received 30 June 1995 - Revised 31 August 1995 - Accepted 4 September 1995)

\begin{abstract}
Body composition was measured in twenty young females aged 19-27 years and eighteen elderly females, aged 65-78 years by densitometry (underwater weighing), deuterium oxide dilution and dual-energy $X$ ray absorptiometry (DXA). From body weight, bone-mineral content, total body water and body density, percentage body fat (BF\%) was calculated using a four-compartment model. BF $\%$ obtained by this fourcompartment model was regarded as a reference method and $\mathrm{BF} \%$ obtained by the single methods were compared with this value. Differences in BF\% from the four-compartment model minus the single methods were 2.1 (SD 1.2) for densitometry, 3.1 (SD 1.8) for DXA and -0.6 (SD 0.9) BF\% for deuterium oxide dilution in the young women. In the elderly women these values were -0.6 (SD 2.3), 5.3 (SD 3.8) and 0.7 (SD 2.2) BF\%. When a three-compartment model (calculated from body density and total body water) was compared with the four-compartment model, the bias was 0.4 (SD 0.3$) \mathrm{BF} \%$ in the young and 0.0 (SD 0.3) BF\% in the elderly women. From the mineral and water fractions in the fat-free mass the true density of the fat-free mass was calculated as 1.1070 (SD 0.0047) $\mathrm{kg} / \mathrm{l}$ in the young females and 1.0970 (SD 0.0088) $\mathrm{kg} / \mathrm{l}$ in the elderly women $(P<0.001)$. This study shows that the single methods have considerable mean and individual biases compared with the four-compartment model, but that a threecompartment model calculated from density and total body water offers an acceptable alternative. The difference in calculated density of the fat-free mass between the young and the elderly women shows the need to adapt Siri's formula for specific groups.
\end{abstract}

Body composition: Densitometry: Dual-energy X-ray absorptiometry: Deuterium oxide dilution

Aspects of body composition are important variables in the assessment of nutritional status (Forbes, 1987) and can be used for the standardization of energy metabolism. Commonly used reference methods for measuring body fat or fat-free mass (FFM) are hydrodensitometry and deuterium oxide dilution, which are based on the classical twocompartment model (Siri, 1961; Forbes, 1987; Lukaski, 1987). A rather new method for estimating body composition is dual-energy X-ray absorptiometry (DXA), which, however, cannot yet be regarded as a 'gold standard' (Roubenoff et al. 1993). The densitometric method assumes a constant density of the FFM of $1 \cdot 100 \mathrm{~kg} / \mathrm{l}$ and of the fat mass (FM) of $0.900 \mathrm{~kg} / \mathrm{l}$ (Siri, 1961). Deuterium oxide dilution (Forbes, 1987) and DXA (Roubenoff $e t$ al. 1993) assume a constant hydration factor of the FFM. Assumptions made in the different methods may not be valid for certain groups of individuals. Elderly women may differ from their younger counterparts in bone mineralization or in hydration of the FFM (Mazess, 1982, 1987; Deurenberg et al. 1989; Baumgartner et al. 1991). Variance in total body water (TBW) and in the ratio of extra- to intracellular fluids can be expected to 
Table 1. Body composition methods used in the present study and their related assumptions

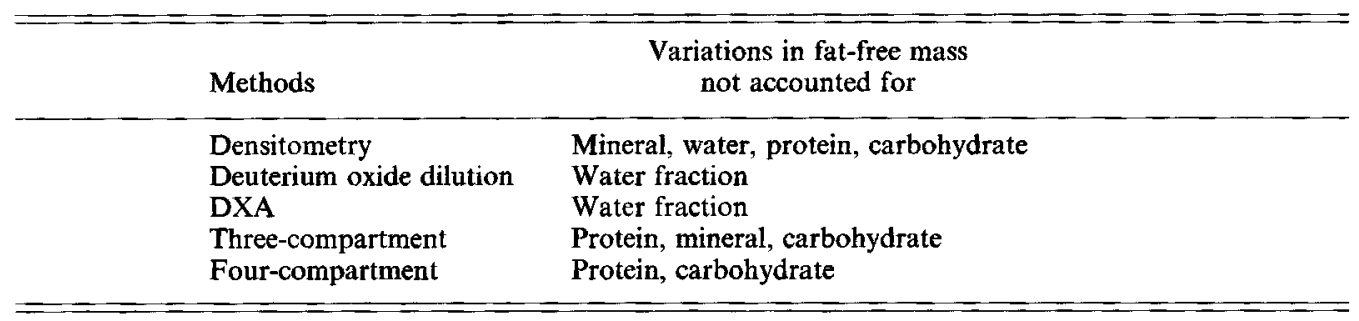

DXA, dual-energy X-ray absorptiometry.

increase with ageing (Schoeller, 1989). Total body protein and Ca decrease with ageing (Heymsfield et al. 1989). The net result of these changes in body composition in the elderly may be a slightly lower mean value of the density of the FFM and an increased variance (Deurenberg et al. 1989; Baumgartner et al. 1991; Reilly et al. 1994). Thus, all methods discussed have certain assumptions which reduce the accuracy in estimating body composition (Table 1).

A three-compartment model, obtained by combining densitometry and deuterium oxide dilution, reduces the opposite influences of the water fraction assumptions of both methods (Pullicino et al. 1990). Heymsfield et al. (1989) developed a four-compartment model by combining non-invasive methods as a chemical approach to assessing body density; this showed close agreement with the density measured by hydrodensitometry and a calculated density of the FFM close to that of previous cadaver studies. A four-compartment model (Baumgartner et al. 1991), including the water and mineral fractions of the body as well as body density, eliminates assumptions for these high variation compartments and therefore improves the accuracy of the body composition estimate.

In the present study percentage body fat $(\mathrm{BF} \%)$ measured by densitometry, deuterium oxide dilution and $\mathrm{DXA}$ and $\mathrm{BF} \%$ calculated by a three-compartment model using body density and TBW was validated against a four-compartment model as a reference in young and elderly caucasian women. The aim of this study was to obtain information about the mean and individual errors in $\mathrm{BF} \%$ when using one of these methods compared with the four-compartment model as the method of reference.

\section{SUBJECTS AND METHODS}

Twenty young women, aged 19-27 years, and eighteen elderly women, aged 65-78 years, participated in the study. They were all Caucasians, were apparently healthy and did not show signs of oedema or dehydration. They were recruited by advertisement, by visiting homes and clubs for the elderly or were included in earlier studies on body composition or energy metabolism at the department. All participants lived in Wageningen and its surroundings. The subjects completed a medical questionnaire which was checked by a physician. Some descriptive characteristics are shown in Table 2.

All measurements were performed in the fasting state at the Department of Human Nutrition of the Wageningen Agricultural University, The Netherlands, except for the DXA measurements which were performed at the Drechtsteden Hospital, Zwijndrecht, The Netherlands. This study protocol was approved by the Medical Ethical Committee of the Department of Human Nutrition.

Body height was measured by means of a wall-mounted stadiometer to the nearest 
Table 2. Descriptive characteristics of the subjects

(Mean values and standard deviations for twenty young and eighteen elderly women)

\begin{tabular}{|c|c|c|c|c|}
\hline & \multicolumn{2}{|c|}{ Young women } & \multicolumn{2}{|c|}{ Elderly women } \\
\hline & Mean & SD & Mean & SD \\
\hline Age (years) & $22 \cdot 5 * * *$ & 1.8 & $71 \cdot 6$ & 3.8 \\
\hline Weight $(\mathrm{kg})$ & $63 \cdot 7$ & $6 \cdot 6$ & $65 \cdot 0$ & 8.5 \\
\hline Height $(\mathrm{m})$ & $1 \cdot 71 * * *$ & 0.06 & 1.60 & 0.05 \\
\hline Body mass index $\left(\mathrm{kg} / \mathrm{m}^{2}\right)$ & $21 \cdot 8^{* * *}$ & 1.9 & $25 \cdot 4$ & 3.9 \\
\hline Body density $(\mathrm{kg} / \mathrm{l})$ & $1 \cdot 0370^{* * *}$ & 0.0066 & 1.0117 & 0.0117 \\
\hline Total body water $(\mathrm{kg})$ & $32 \cdot 5^{* * *}$ & 2.9 & $29 \cdot 0$ & $2 \cdot 5$ \\
\hline Bone-mineral content $(\mathrm{g})$ & $2644^{* * *}$ & 274 & 1987 & 234 \\
\hline Water fraction of FFM & $0.723^{* * *}$ & 0.010 & 0.737 & 0.025 \\
\hline Mineral fraction of FFM & $0.075^{* * *}$ & 0.005 & 0.064 & 0.006 \\
\hline $\begin{array}{l}\text { Body fat from four- } \\
\text { compartment model }(\%)\end{array}$ & $29 \cdot 4^{* * *}$ & $3 \cdot 2$ & $38 \cdot 8$ & 5.9 \\
\hline
\end{tabular}

FFM, fat-free mass.

*** Mean values were significantly different from those for the elderly women, $P<0.001$.

$0.001 \mathrm{~m}$. Body weight was measured after voiding to the nearest $0.05 \mathrm{~kg}$ with a digital scale (Berkel ED60T, Rotterdam, The Netherlands), with subjects wearing a swimsuit only. No correction for the weight of the swimsuit was made.

Body density was calculated from weight in air and from underwater weight with simultaneous determination of the residual lung volume by He dilution (Spiro Junior, Jaeger GmbH, Würtzburg, Germany). The underwater weight was measured in duplicate to the nearest $0.001 \mathrm{~kg}$ with a digital scale (3826 MP 81, Sartorius, Göttingen, Germany). The within-subject variability in body density with this system is $0.0019 \mathrm{~kg} / 1$ (Jansen et al. 1992). BF\% was calculated from body density using Siri's (1961) equation.

Body composition was also determined by the Lunar DPX whole body X-ray densitometer (Lunar DPX, 1992; software version 1.3z) at medium scan mode. The variables measured by DXA were bone-mineral content $(\mathrm{g})$, bone-mineral density $\left(\mathrm{g} / \mathrm{cm}^{2}\right)$, body FM (g), BF\%, soft-tissue mass (g), and sum of total body tissues (g).

Total body water (TBW) was obtained from deuterium oxide dilution (Forbes, 1987). An accurately weighed dose of about $15 \mathrm{~g}$ deuterium oxide was taken orally by the subjects. After $2 \cdot 5-3 \mathrm{~h}$ dilution time a venous blood sample of $10 \mathrm{ml}$ was drawn. Plasma was separated and stored at $-20^{\circ}$ until analysis. Deuterium in plasma was determined after sublimation, by infrared spectroscopy (Lukaski \& Johnson, 1985). TBW (kg) was calculated using a 0.95 correction factor for non-aqueous dilution of deuterium oxide (Forbes, 1987). FFM was calculated assuming a hydration factor of 0.735 (Lukaski \& Johnson, 1985). BF\% was then calculated as $100 \times$ (weight-FFM)/weight.

From body density and TBW, BF\% was calculated using a three-compartment model as described by Siri (1961). The formula used was:

$$
\mathrm{BF} \%=100 \times(2 \cdot 118 / \mathrm{Db}-0.78 \times \mathrm{A}-1 \cdot 354),
$$

where $\mathrm{Db}$ is body density and $\mathrm{A}$ is the water fraction of body weight (Siri, 1961).

$\mathrm{BF} \%$ was also calculated using the four-compartment model (including FM, TBW, mineral and a remaining compartment, consisting of protein and carbohydrate) described by Baumgartner et al. (1991). BF\% was then calculated with the formula:

$$
\mathrm{BF} \%=205 \times(1.34 / \mathrm{Db}-0.35 \times \mathrm{A}+0.56 \times \mathrm{M}-1),
$$


where $\mathrm{Db}$ is the body density, $\mathrm{A}$ is the water fraction of body weight and $\mathrm{M}$ is the mineral fraction of body weight as obtained from DXA. BF\% calculated with this fourcompartment model was regarded as the method of reference. The SPSS/PC program (Statistical Package for the Social Sciences, 1990) was used for statistical calculations. The mean differences between estimates of BF\% were calculated and tested for statistical significance by paired $t$ tests for young and elderly separately. Differences between young and elderly women were tested by ANOVA. Correlations are Pearson's product moment correlation coefficients. Significance was inferred at $P<0.05$. All results are expressed as means and standard deviations (SD).

\section{RESULTS}

Table 2 gives some characteristics of the subjects. The elderly had a lower body height, a higher BMI, a lower body density, a lower TBW and a lower bone-mineral content. Body weight did not differ between the age groups. Table 2 also shows BF\% as well as water and mineral fractions of the FFM calculated with the four-compartment model. From these data the density of the FFM was calculated as $1 \cdot 1070$ (SD 0.0047) $\mathrm{kg} / \mathrm{l}$ in the young and 1.0970 (SD 0.0088$) \mathrm{kg} / 1$ in the elderly women $(P<0.001)$.

All measures of $\mathrm{BF} \%$ were highly correlated, correlation coefficients in the young women ranging from 0.81 to 0.99 and in the elderly women from 0.75 to 0.99 (all $P<0.001$ ). The lowest correlation was between body fat from densitometry and body fat from deuterium oxide dilution, the highest correlation was between the three- and the four-compartment models.

In Table 3 the mean differences in body fat of the separate methods with the fourcompartment model are compared. In the younger females all differences were significantly different from zero, whereas in the older females only the DXA method gave a significantly different mean BF\% compared with the four-compartment model. The highest SD in both the young and the elderly groups was that for the differences of body fat from DXA and the four-compartment model. It is noteworthy that much larger SD were observed for the older females, except for the three-compartment model. Fig. 1 shows the individual errors of the $\mathrm{BF} \%$ from densitometry, from deuterium oxide dilution and from the mean value of densitometry and deuterium oxide dilution.

In Table 4 the correlations of the differences of $\mathrm{BF} \%$ from the four-compartment model and the other methods with the water fraction and mineral fraction of the FFM are given for the young and elderly women. Figs. 2 and 3 show the dependency of $B F \%$ on the water fraction and the mineral fraction in the FFM. It is clear that at lower values of the water fraction of the FFM the densitometric method underestimated BF\%. At lower values of mineral fraction the densitometric method tended to overestimate. When the difference in mineral fraction between young and elderly women was controlled for (ANOVA), the mean bias of the three-compartment model was, in both groups, $0.2 \%$ body fat. In Table 5 the means and SD of the differences in $\mathrm{BF} \%$ between the single methods used are listed. Generally, the individual differences were higher in the elderly, which indicates stronger violations of assumptions in the individual elderly subjects.

\section{DISCUSSION}

The subjects in the present study were recruited only in the surroundings of Wageningen. Therefore the sample cannot be regarded as representative of Caucasian Dutch young and elderly women. The elderly women were apparently healthy and mobile, and probably more physically active than average as they also volunteered to take part in a study on 
Table 3. Differences between percentage body fat estimated by the four-compartment model and percentage body fat estimated by other methods, for young and elderly women (Mean values and standard deviations for twenty young and eighteen elderly women)

\begin{tabular}{|c|c|c|c|c|}
\hline & \multicolumn{2}{|c|}{ Young women } & \multicolumn{2}{|c|}{ Elderly women } \\
\hline & Mean & SD & Mean & SD \\
\hline \multicolumn{5}{|c|}{ Four-compartment model minus: } \\
\hline Densitometry & $2 \cdot 1^{*}$ & 1.2 & -0.6 & $2-3$ \\
\hline DXA & $3 \cdot 1^{*}$ & 1.8 & $5 \cdot 3^{*}$ & 3.8 \\
\hline Deuterium oxide dilution & $-0 \cdot 6^{*}$ & 0.9 & 0.7 & $2 \cdot 2$ \\
\hline Three-compartment model & $0 \cdot 4^{*}$ & 0.3 & 0.0 & $0 \cdot 4$ \\
\hline
\end{tabular}

DXA, dual-energy X-ray absorptiometry.

* Mean differences were significantly different from zero, $P<0.05$.

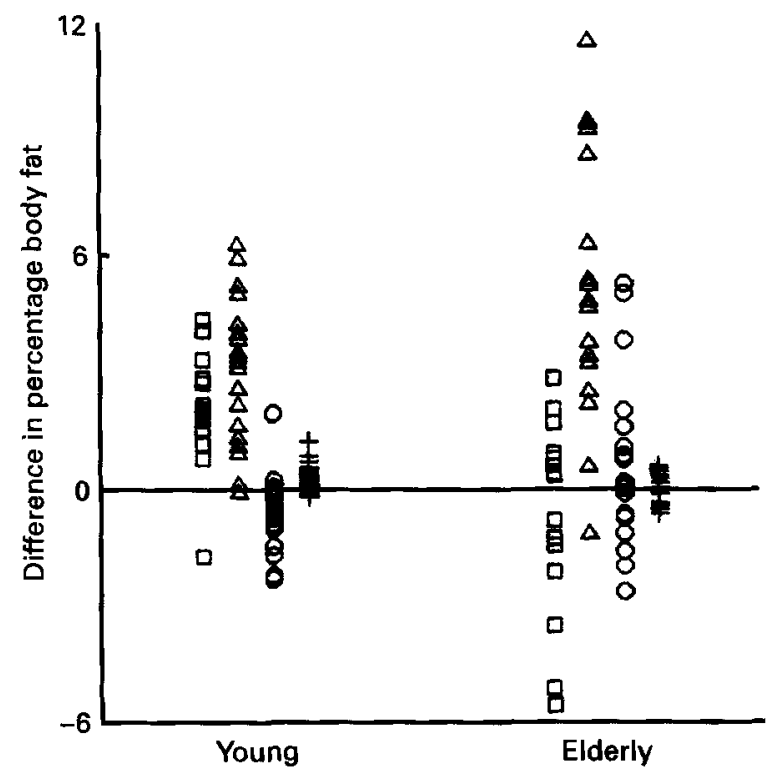

Fig. 1. Individual differences in the body-fat values of young and elderly women obtained from densitometry ( $\square$ ), deuterium oxide dilution $(\triangle)$, dual-energy $X$-ray absorptiometry $(O)$ and a three-compartment model $(+)$, from those obtained using a four-compartment model.

energy expenditure. However, comparison with values from the Central Bureau of Statistics (Centraal Bureau voor de Statistiek, 1994) revealed that weight and height of the two groups studied were comparable with those for Dutch women of the same age (young: $63.2 \mathrm{~kg}, 1.69 \mathrm{~m}$; elderly: $68.8 \mathrm{~kg}, 1.64 \mathrm{~m}$ ).

Although the correlation between several estimates of body fat was high, there were considerable differences in individual as well as in mean values (Fig. 1, Tables 3 and 5). Siri (1961) estimated the maximal error of the two-compartment model to be about $4 \%$ of body weight. Most of this error was attributed to biological variability and only a small fraction to measurement error. A three-compartment model, including density and TBW, reduced the maximal error to about $2 \%$ of body weight, according to Siri's (1961) calculations. In 
Table 4. Correlations between differences of predicted body fat from a four-compartment model and densitometry, dual-energy $X$-ray absorptiometry $(D X A)$, deuterium oxide dilution and a three-compartment model with the water and mineral fractions of the fat-free mass

\begin{tabular}{|c|c|c|c|c|}
\hline & \multicolumn{2}{|c|}{ Young women } & \multicolumn{2}{|c|}{ Elderly women } \\
\hline & TBWFFM & MFFM & TBWFFM & MFFM \\
\hline \multicolumn{5}{|c|}{ Four-compartment model minus: } \\
\hline Densitometry & $-0.81 *$ & $0.76^{*}$ & $-0.94 *$ & $0.47 *$ \\
\hline DXA & 0.40 & 0.31 & $0.70^{*}$ & -0.08 \\
\hline Deuterium oxide dilution & $0.99 *$ & -0.25 & $0.99 *$ & -0.19 \\
\hline Three-compartment model & $-0 \cdot 25$ & $0.84^{*}$ & $0.73^{*}$ & $0.53^{*}$ \\
\hline
\end{tabular}

TBWFFM, water fraction of the fat-free mass from four-compartment model; MFFM, mineral fraction of the fat-free mass from four-compartment model.

* $P<0 \cdot 05$.

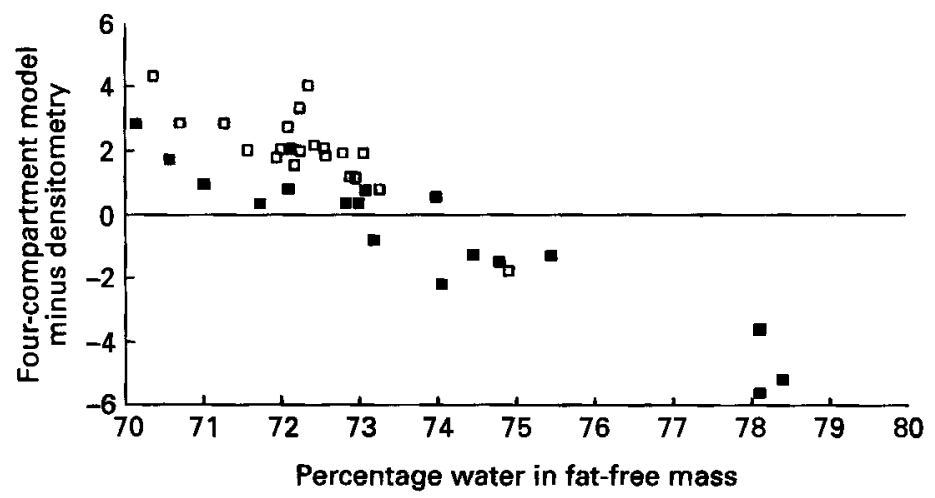

Fig. 2. Individual differences in body-fat values for young ( $\square$ ) and elderly ( $\square$ ) women, obtained by densitometry and by a four-compartment model, in relation to the water fraction of the fat-free mass.

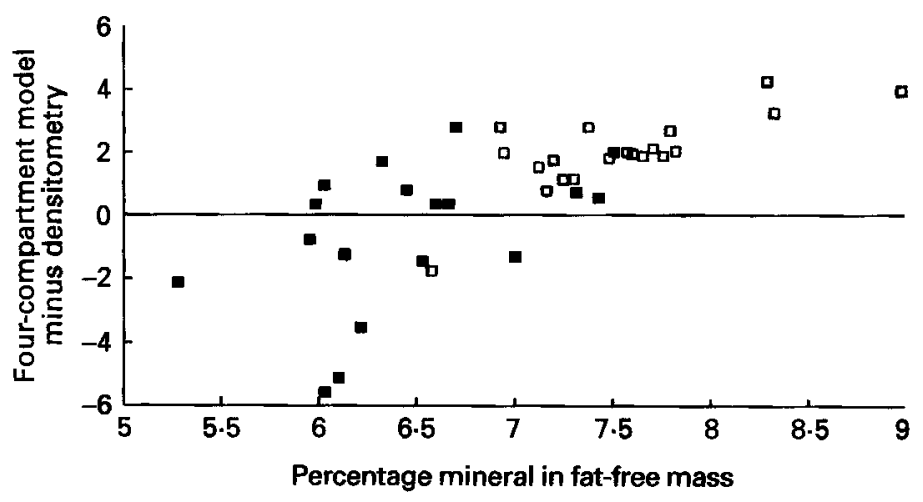

Fig. 3. Individual differences in body-fat values for young $(\square)$ and elderly $(\square)$ women, obtained by densitometry and by a four-compartment model, in relation to the mineral fraction of the fat-free mass. 
Table 5. Differences between percentage body fat estimated by different methods, for young and elderly women

(Mean values and standard deviations for twenty young and eighteen elderly women)

\begin{tabular}{lccccc}
\hline & \multicolumn{2}{c}{ Young women } & & \multicolumn{2}{c}{ Elderly women } \\
& Mean & SD & Mean & SD \\
\hline Densitometry minus DXA & $1 \cdot 0$ & $2 \cdot 3$ & $5 \cdot 8^{*}$ & $5 \cdot 5$ \\
Densitometry minus deuterium oxide dilution & $-2 \cdot 7^{*}$ & $2 \cdot 1$ & 4.5 \\
DXA minus deuterium oxide dilution & $-3 \cdot 7^{*}$ & $1 \cdot 7$ & $-4^{*}$ & $2 \cdot 6$ \\
\hline
\end{tabular}

DXA, dual-energy X-ray absorptiometry.

* Mean differences were significantly different from zero, $P<0.05$.

the present study the maximal individual error of the two-compartment model (densitometry as well as deuterium oxide dilution), with the four-compartment model as a reference, was about $4 \%$ in the younger women and about $5 \%$ in the elderly women, whereas the maximal mean errors were $2 \cdot 1$ and $0.6 \%$ in the young and elderly women respectively. However, in the young group densitometry underestimated BF\% whereas in the older group densitometry slightly overestimated BF\% (Table 3). The threecompartment model reduced the mean bias as well as the individual error markedly, which is illustrated in Fig. 1 and can also be read from Table 3.

The addition of bone mineral as an independent variable in the four-compartment model provided only a small increase in accuracy in the two age groups. The differences between the four-compartment model and the three-compartment model were small (Table 3 and Fig. 1), and statistically significant only in the younger group. Baumgartner et al. (1991) in studying elderly males and females also concluded that addition of the mineral fraction in the four-compartment model provided only a marginal, non-significant, increase in accuracy. This is to be expected as addition of the mineral fraction to a three-compartment model may only add to the accuracy when the mineral:protein ratio varies widely. The differences in mineral:protein ratio between young and elderly which can be calculated from Table 2 may have been too small to have an effect. The assumptions of each method can reduce its accuracy. The relative (to the four-compartment model) underestimation of BF\% from DXA (Table 3) may be due to the limitations of this technique (Laskey et al. 1992; van Loan \& Mayclin, 1992; Roubenoff et al. 1993). Roubenoff et al. (1993) pointed out that DXA measurements are not free of the assumption of uniform hydration. This was confirmed by the correlation found in the present study between the difference in $\mathrm{BF} \%$ (four-compartment minus DXA) and the water fraction of the FFM in the young as well as in the elderly women (Table 4).

Deuterium oxide dilution is known to overestimate TBW because of an exchange of $\mathrm{H}$ with $\mathrm{COOH}$ and $\mathrm{OH}$ groups. Culebras \& Moore (1977) calculated a $5 \%$ non-aqueous exchange and Schoeller \& Jones (1987) an exchange of 4 (SD 1) \%. In the present study a $5 \%$ correction factor was used, according to Forbes (1987). In spite of this correction factor, deuterium oxide dilution overestimated $\mathrm{BF} \%$ in the young using the fourcompartment model as a reference. This indicates that the assumed correction factor $(5 \%)$ could have been too high. The assumption of $73.5 \%$ water in the FFM (Lukaski \& Johnson, 1985) was, however, very close to the measured means in both groups (Table 2). Water fractions which are smaller than the assumed $73.5 \%$ cause an overestimation of $\mathrm{BF} \%$ by deuterium oxide dilution (Pullicino et al. 1990). 
Densitometry underestimated $\mathrm{BF} \%$ in the young and overestimated $\mathrm{BF} \%$ in the elderly. The difference in the bias between the young and elderly women was apparently due to the differences in water and mineral fractions of FFM between the age groups, according to the relation as shown in Figs. 2 and 3. In elderly women the water fraction of FFM (and its SD) was significantly greater than that in the young (Table 2). The mineral fraction was significantly smaller in the elderly compared with the young. In the present study these differences resulted in a relative overestimation of $\mathrm{BF} \%$ in the elderly compared with a relative underestimation in the young.

The calculated mean densities of FFM in young and elderly women were $1 \cdot 1070 \mathrm{~kg} / 1$ and $1.0970 \mathrm{~kg} / 1$ respectively. The mean value for both age groups together was $1 \cdot 1032$ (SE 0.0085) kg/1, which is close to the value used in Siri's (1961) formula and close to the value reported by Heymsfield et al. (1989). The difference in calculated density of the FFM between the young and the elderly women shows the need to adapt Siri's (1961) formula for specific groups, especially in comparative studies.

The four-compartment model was significantly more accurate than densitometry, deuterium oxide dilution or DXA alone, both in the young as well as in the elderly. However, as a less expensive but good alternative a three-compartment model may be used. This three-compartment model not only resulted in a small mean bias, but also the individual differences from the four-compartment model were very small (Fig. 1). The choice of using a four-compartment model, instead of other less laborious two- or threecompartment models, will depend on the aim of the study and the required accuracy and precision of the results. In studies in which differences in energy metabolism between groups (in which assumptions for body composition techniques may differ) are investigated, the only alternative leading to unbiased results may be a four-compartment model. In conclusion: $\mathrm{BF} \%$ values obtained from densitometry, deuterium oxide dilution and DXA showed sometimes marked differences, especially at an individual level, from the value obtained by a four-compartment model in which the variations in body water and minerals in the body were accounted for. The bias was different in young and elderly women, indicating age-dependent differences in body composition. A three-compartment model, using body density and deuterium oxide dilution, had a relatively small mean bias in both age groups, whereas the individual errors did not exceed $1.2 \%$ body fat.

The authors would like to thank the subjects for their enthusiastic cooperation, Mr Martin Koenders from Sandoz Nutrition, The Netherlands for financial support and Mr Mark Stoute from the Drechtsteden Hospital in Dordrecht for the performance of the DXA measurements. Mrs Annemien Haveman-Nies, Mrs Connie van Iperen, Mrs Diny Laan and Mr Frans J. M. Schouten helped with the performance of the measurements.

\section{REFERENCES}

Baumgartner, R. N., Heymsfield, S. B., Lichtman, S., Wang, J. \& Pierson, R. N. (1991). Body composition in elderly people: effect of criterion estimates on predictive equations. American Journal of Clinical Nutrition $\mathbf{5 3}$, 1345-1353.

Centraal Bureau voor de Statistiek (1994). Statistisch Jaarboek 1994, p. 486. 's Gravenhage: sdu/uitgeverij, CBSpublikaties.

Culebras, J. M. \& Moore, R. D. (1977). Total body water and the exchangeable hydrogen. I. Theoretical calculations of nonaqueous exchangeable hydrogen in man. American Journal of Physiology 232, R54-R59.

Deurenberg, P., Weststrate, J. A. \& van der Kooy, K. (1989). Is an adaptation of Siri's formula for the calculation of body fat percentage from body density in the elderly necessary? European Journal of Clinical Nutrition 43, $559-568$.

Forbes, G. B. (1987). Human Body Composition. Growth, Aging, Nutrition, and Activity. New York: SpringerVerlag.

Heymsfield, S. B., Wang, J., Kehayias, J., Heshka, S., Lichtman, S. \& Pierson, R. N. (1989). Chemical 
determination of human body density in vivo: relevance to hydrodensitometry. American Journal of Clinical Nutrition 50, 1282-1289.

Jansen, D. F., Korbijn, C. M. \& Deurenberg, P. (1992). Variability of body density and body impedance at different frequencies. European Journal of Clinical Nutrition 46, 865-871.

Laskey, M. A., Lyttle, K. D., Flaxman, M. E. \& Barber, R. W. (1992). The influence of tissue depth and composition on the performance of the Lunar dual-energy X-ray absorptiometer whole-body scanning mode. European Journal of Clinical Nutrition 46, 39-45.

Lukaski, H. C. (1987). Methods for the assessment of body composition: traditional and new. American Journal of Clinical Nutrition 46, 437-456.

Lukaski, H. C. \& Johnson, P. E. (1985). A simple, inexpensive method of determining total body water using a tracer dose of $\mathrm{D}_{2} \mathrm{O}$ and infrared absorption of biological fluids. American Journal of Clinical Nutrition 41, $363-370$.

Lunar DPX (1992). Technical Manual. Madison, Wisconsin: Lunar.

Mazess, R. B. (1982). On aging bone loss. Clinical Orthopaedics 165, 329-351.

Mazess, R. B. (1987). Bone density in diagnosis of osteoporosis: thresholds and breakpoints. Calcified Tissue International 41, 117-118.

Pullicino, E., Coward, W. A., Stubbs, R. J. \& Elia, M. (1990). Bedside and field methods for assessing body composition: comparison with the deuterium dilution technique. European Journal of Clinical Nutrition 44 , 753-762.

Reilly, J. J., Murray, L. A., Wilson, J. \& Durnin, J. V. G. A. (1994). Measuring the body composition of elderly subjects: a comparison of methods. British Journal of Nutrition 72, 33-44.

Roubenoff, R., Kehayias, J. J., Dawson-Hughes, B. \& Heymsfield, S. D. (1993). Use of dual-energy X-ray absorptiometry in body-composition studies: not yet a 'gold standard'. American Journal of Clinical Nutrition $58,589-591$.

Schoeller, D. A. (1989). Changes in total body water with age. American Journal of Clinical Nutrition 50, Suppl., 1176-1181.

Schoeller, D. A. \& Jones, P. J. H. (1987). Measurement of total body water by isotope dilution : a unified approach to calculation. In In Vivo Body Composition Studies, pp. 131-137 [K. J. Ellis, S. Yasumura and W. D. Morgan, editors]. London: Institute of Physical Sciences in Medicine.

Siri, W. E. (1961). Body composition from fluid spaces and density, analysis of methods. In Techniques for Measuring Body Composition, pp. 223-244 [J. Brozek and A. Henschel, editors]. Washington, DC: National Academy of Sciences.

Statistical Package for the Social Sciences (1990). SPSS/PC V4.0 Manuals. Chicago, IL: SPSS Inc.

van Loan, M. D. \& Mayclin, P. L. (1992). Body composition assessment: dual-energy X-ray absorptiometry (DXA) compared to reference methods. European Journal of Clinical Nutrition 46, 125-130. 